\title{
Rethinking mental disorders: The role of learning and brain plasticity
}

\author{
Sarah E. Morris*, Judith M. Rumsey and Bruce N. Cuthbert \\ Division of Adult Translational Research, National Institute of Mental Health, Bethesda, MD, USA
}

\begin{abstract}
Recent research in neurodevelopment, neuroplasticity and genetics is providing new insights into the etiogenesis of psychopathology, but progress in treatment development has been hampered by reliance on diagnostic categories that are characterized by heterogeneity and based primarily on phenomenology. The NIMH Research Domain Criteria (RDoC) initiative seeks to provide a neuroscience-based nosological framework for future research on psychopathology, categorizing individuals for research purposes using a dimensional approach that capitalizes on advances in modern neuroscience. These scientific advances and new approaches to classification can inform the development of novel, circuit-based interventions and the personalization of treatment. In this paper, we review key advances areas in clinical neuroscience, describe the RDoC project and highlight some emerging treatment approaches that are consistent with these developments.
\end{abstract}

Keywords: Psychiatric diagnosis, RDoC, neuroplasticity, psychiatric treatment

The development of novel tools and enhanced capacities to measure and manipulate brain activity has ushered in a new era of neuroscience-informed approaches to mental disorders. In this new perspective, rather than being characterized by presenting signs and symptoms, mental disorders are conceptualized as having their basis in dysfunctional neural circuits. However, identifying the nature of these circuit dysfunctions is challenging due to several common features of mental disorders. Specifically, many mental disorders have a pattern of insidious onset with the etiogenesis of pathophysiology preceding the onset of frank symptoms, perhaps by years. In contrast to neurological disorders, most mental disorders are not associated with localized brain lesions; rather, they have their substrates in widely distributed limbic, prefrontal and fronto-striatal circuits, which presents a challenge for the identification of appropriate targets

*Corresponding author: Sarah E. Morris, Division of Adult Translational Research, National Institute of Mental Health, 6001 Executive Blvd., Bethesda, MD 20892, USA. Tel.: +1 301443 9233; Fax: +1 301443 4611; E-mail: sarah.morris@ nih.gov. for intervention. In this article, we briefly highlight some of the research on neurodevelopment, neuroplasticity and epigenetics that provides a basis for this reconceptualization of mental disorders, describe the National Institute of Mental Health's (NIMH) initiative to create a new nosology of mental disorders for research purposes, and review some of the emerging intervention research and clinical approaches that target domains of functioning and dysfunctional circuits.

\section{Neurodevelopment neuroplasticity and epigenetics}

For decades, accumulating evidence has supported neurodevelopmental and genetic contributions to many mental disorders, including schizophrenia, depression and bipolar disorder (Ishizuka et al., 2006; Rapoport et al., 2005; Stevens et al., 2010; Weinberger, 1987). Simultaneously, a wealth of new science focused on understanding the mechanisms of neuroplasticity and epigenetics in healthy organisms (Allen, 2008; 
Mehler, 2008b) blurred the conceptual lines that previously separated genetic factors from environmental ones. Recent advances in understanding the complex interplay of developmental, genetic and environmental factors point to the importance of ongoing brain changes subsequent to experience, exposure and learning. Conceptualizations of mental disorders have begun to incorporate the complexity that arises from increased understanding of the normative neural changes that occur throughout the lifespan amid continuous neuroplasticity and under the influence of genes whose expression is impacted by non-genetic factors. Many classes of mental illness can be described as maladaptive patterns of thought, emotion and behavior resulting from suboptimal neuroplastic changes occurring at various developmental time points.

Although a great deal of empirical attention has been devoted to understanding the links between neurodevelopment during the critical prenatal period and later mental illness, there is evidence that brain development involving the growth of new neurons continues during adulthood and is important in mental disorders including depression, bipolar disorder, schizophrenia and addiction (Eisch et al., 2008; Phillips et al., 2008). Neurogenesis has been documented in the hippocampal dentate gyrus and anterior subventricular zone in adult mammals (Balu et al., 2009) and this neurogenesis appears to recapitulate prenatal neuronal development (Duan et al., 2008). The interactions between prenatal and later developmental events are increasingly the focus of study and this expanded neurodevelopmental perspective can help to explain features of some mental disorders, such as peri-adolescent age-of-onset, which have not been satisfactorily explained in prior illness models. For example, demonstrating how a prenatal event might impact later neural changes, in-utero disruption of the Disrupted-in-Schizophrenia-1 (DISC1) gene in mice resulted in post-pubertal changes in the organization of neural circuits, dopamine function, and behavior that are consistent with schizophrenia, including hyper-responsivity to amphetamine, and some of these changes were reversible with the administration of antipsychotic medication (Niwa et al., 2010). Other work has demonstrated complex additive effects and interactions between DISC1 and other genes that affect neurogenesis in adult mice which are consistent with epistatic patterns observed in individuals with schizophrenia (Kang et al., 2011). Although structural neuroimaging can provide some evidence of neurodevelopmental changes (Pantelis et al., 2005), studies of post-natal neurogenesis in adult humans have relied largely on analysis of post-mortem tissue. For example, diminished neural stem cell proliferation has been found in hippocampal tissue samples from individuals with schizophrenia (Reif et al., 2006) and the proliferative effects of antidepressant medications suggest a role for hippocampal neurogenesis in depression treatment (Boldrini et al., 2009). Postmortem research approaches preclude longitudinal studies of illness course or treatment response, but efforts to develop novel neuroimaging techniques sensitive to in-vivo neurogenesis in humans are in progress (CouillardDespres et al., 2011).

In addition to neurodevelopmental processes involving the generation of new neurons, neuroplasticity is also achieved via ongoing changes in the structure of existing neurons and the function of neural circuits in response to intrinsic and extrinsic stimuli (Cramer et al., 2011; Fox, 2009). The changes may be local or widely-distributed and result in adaptive or maladaptive alterations in brain function and behavior. Neuroplasticity is increasingly understood as "an integral property and the obligatory consequence of each sensory input, motor act, association, reward signal, action plan, or awareness," rather than a process that is activated only at certain developmental stages or in response to brain injury (Pascual-Leone et al., 2005). Many of the principles of neuroplasticity have been identified by studying changes in representational maps and patterns of functional recovery following stroke or brain injury, or changes in brain morphology and function at various stages of learning. In the adult brain, neuroplasticity appears to follow a two-stage process characterized by rapid and transient changes in the functioning of existing neural pathways followed by more prolonged changes in the organization of neural pathways (Pascual-Leone et al., 2005) resulting from changes in neural features such as axon integrity and diameter, myelination, dendritic branching, and synaptic density which are observed following periods of practice lasting from days to weeks, (Zatorre et al., 2012). Importantly for the consideration of mental disorders and their treatment, plasticity-related changes in neural organization are observed not only in association with motor learning but also following mental rehearsal (e.g., Gentili et al., 2010) and learning of new cognitive tasks (e.g., Takeuchi et al., 2011).

Neuroplasticity may be the mechanism by which experiences such as psychological trauma, substance use, social interactions, and stress contribute to the 
onset and course of mental disorders (Goto et al., 2010). Because some mental disorders may result from longstanding neurodevelopmental changes in distributed neural circuits, it is challenging to determine how neuroplasticity might play a role in the etiology of mental illness by perpetuating abnormal connectivity or in recovery by serving a compensatory purpose. Increasing evidence suggests that the balance between plasticity and stability is disrupted in distinct ways for different classes of disorders. For example, based on physiological changes observed in amygdala neurons in a rodent models, it has been hypothesized that hyperplasticity may play a role in autism (Markram et al., 2007). In schizophrenia, various abnormalities in neural structure and function, including reduced dendritic complexity and length, decreased synaptic density, and disruptions of neural connectivity are suggestive of hypoplasticity, likely related to the effects of various risk genes (Balu et al., 2011; Lewis et al., 2007). In depression, hypoplasticity in frontal and hippocampal structures and hyperplasticity in the amygdala may be among the mechanisms by which stress impacts this disorder (Drevets, 2004; Pittenger et al., 2007). Patterns of remission and relapse in mood disorders, with relapses being predictive of worse clinical outcomes, suggest the involvement of maladaptive plasticity (Post, 2007; Schloesser et al., 2007). Cycles of increasing and decreasing neuroplasticity occurring sequentially in mesolimbic dopamine (DA), nucleus accumbens, prefrontal, and amygdala circuits are hypothesized to be involved in the transition from occasional, controlled substance use to the cycle of addiction (Koob et al., 2009). New insights into neuroplasticity hold promise for the development of targeted interventions that capitalize on neurons' extensive potential for change.

Our understanding of both neurodevelopment and neuroplasticity is increasingly informed by studies of epigenetic processes, such as DNA methylation and acetylation, which cause tissue-specific changes in gene expression, but not genotype, following exposure to a signal or stimulus (Feil, 2008). The range of processes and behaviors that have been demonstrated to be impacted by epigenetic changes is large, including thermoregulatory, homeostatic and metabolic controls, feeding and circadian rhythms, and reproductive and maternal behavior (Meaney, 2010; Mehler, 2008a). Epigenetic processes have been shown to play a role in long-term neuroplasticity, learning, and memory (Dulac, 2010; Hsieh et al., 2010) and a majority of the genes that are affected by epigenetic changes and then inherited by offspring are expressed in brain tissue (Wilkinson et al., 2007). Epigenetic changes in gene activity are reversible under some circumstances but also may persist in an organism and in its offspring (Richards, 2006), and thus may account for certain psychiatric outcomes that involve complex interactions between genotype and internal and external environments.

Understanding of epigenetic processes promises to shed light on some of the persistently challenging features of mental disorders, such as the variable patterns of risk and inheritance within and among mental disorders, trajectories of remission and relapse, and the presence of overlapping genetic variants among disorders. A variety of epigenetic mechanisms has been linked to neurodevelopment and neuroplasticity in diverse mental disorders (Hsieh et al., 2010). Some of these have been incorporated into models that are disease-specific and others are focused on symptoms that span disorders. In disease-specific examples, Mateus-Pinheiro and colleagues (2011) propose a neuro-epigenetic model of depression in which epigenetic regulation of hippocampal neurogenesis is linked to the behavioral and cognitive changes characteristic of the disorder; also, epigenetic changes in GABAergic interneurons following prenatal stress have been shown to induce abnormalities in methylation and behavior in a mouse model of schizophrenia (Matrisciano et al., 2012). One of the changes observed by Matrisciano and colleagues following prenatal stress was increased activity of a methyl binding protein (MECP2) that has recently been examined in studies of epigenetic processes in Rett syndrome. In a mouse model of Rett syndrome, activation of the MECP2 gene reversed the neuronal and behavioral abnormalities characteristic of the disorder, suggesting that, contrary to prior conceptualizations, Rett syndrome is not an irreversible neurodevelopmental disorder, but rather reflects the absence of a gene needed to sustain normal neurological function following early brain development (Guy et al., 2007; Robinson et al., 2012). The applicability of the Rett syndrome example to most mental disorders may be limited because of its single-gene basis, but it is nonetheless intriguing in its relevance to disorders that also appear to be neurodevelopmental in nature.

In contrast, other work has focused on epigenetic processes that might be relevant across mental disorders. For example, observation of epigenetic effects of childhood abuse on HPA function and hippocampal 
glucocorticoid receptor expression in brain tissue of suicide victims (McGowan et al., 2009) suggests a mechanism by which the social environment and distress might impact the functioning of a neural circuit. In a postmortem study comparing individuals with schizophrenia and bipolar disorder to healthy controls, methylation differences were found in genetic loci involved in brain development and stress response, suggesting epigenetic similarities in psychosis across disorders (Mill et al., 2008; Pidsley et al., 2011).

These and other new discoveries about the complex interplay of neurodevelopment, neurogenesis and epigenetics present challenges to our current conceptualizations of mental disorders by illustrating the many ways in which the functioning of neural circuits can be altered, resulting in clinical outcomes that do not necessarily align with traditional diagnostic distinctions but which are consistent with the phenomenological and genetic heterogeneity observed within diagnostic categories and the high rates of co-occurrence among diagnoses. The studies reviewed above (and many others) demonstrate relationships between genes, neural circuits, and behavior and inform our understanding of important disease-related phenotypes, but they do not typically explain the entirety of a categorical diagnosis. A single disorder may involve multiple pathophysiological pathways (Gallinat, 2008), each of which is impacted by one or more genes (Buonanno, 2010) and these features do not abide by diagnostic distinctions. Our current diagnostic systems presume clear boundaries among disorders and between "normalcy" and "disorder," are silent with regard to the roles of genes and neural circuits, and do not facilitate meaningful integration of these types of discoveries. Thus, it is necessary to reconsider our approach to the classification of individuals for research purposes.

\section{A novel nosological approach}

Current nosologies of mental disorders such as those included in the American Psychiatric Association's Diagnostic and Statistical Manual (DSM) and the World Health Organization's International Classification of Disease (ICD) provide diagnostic guidelines and criteria that are based on the identification of clusters of symptoms via observation of behavior and self-report of experience. These diagnostic classifications evolved from conceptualizations that pre-date neuroscience and do not incorporate new knowledge derived from a multiplicity of neuroscience methods. New understanding of the combined impact of genetic and environmental factors on neural function demonstrate their importance to behaviors and experiences that are highly relevant to mental disorders but which do not necessarily map onto existing diagnostic categories (Meyer-Lindenberg et al., 2012). Findings from recent studies of genetic association (van Veen et al., 2012), functional genomics (Ayalew et al., 2012) and chromosomal abnormalities (Talkowski et al., 2012) converge on a pattern of overlapping disruption among disorders rather than disorder-specific alleles or abnormalities. This lack of diagnostic dissociation may contribute significantly to the unsatisfying rate of progress in discovering disease-related genes and developing new treatments, and reinforces the need for a nosological system that is based on knowledge of brain circuits and their associated genes, molecules and behavior.

On a practical level, although categorical diagnostic approaches have yielded increased reliability and precision in diagnosis that have benefited clinical practice and research, these types of nosologies confer some important limitations. Specifically, heterogeneity among symptoms within diagnoses, high rates of co-occurrence of disorders, and frequent "NOS" (not otherwise specified) diagnoses all suggest that a significant proportion of patients "fall between the categories." The result is that, for research purposes, many patients are either excluded from participating because they do not meet the diagnostic criteria of interest or they are included in a diagnostic category for which they are not well-suited for purposes of conducting between-group comparisons; either outcome threatens the validity of the results of the research endeavor.

To address these issues, the National Institute of Mental Health (NIMH) has initiated the development of a new framework for the classification of mental disorders for research purposes which will provide an alternative approach to characterizing disorders, elucidating underlying mechanisms, and developing new or enhanced treatments. The Research Domain Criteria (RDoC) project applies an integrative, dimensional approach that is anchored in circuit neuroscience, focusing the study of psychopathology on core domains and their associated constructs as measured using different units of analysis. Consistent with NIMH's strategic plan (2008), specifically Objective 1.4 to "Develop, for research purposes, new ways of classifying mental disorders based on dimensions of observable behavior and neurobiological measures," 
the RDoC framework represents a tool of translational neuroscience that provides a novel, unifying perspective for the study of mental disorders by integrating new neuroscience approaches with behavioral research. The goal is to optimize the translation of this combined knowledge into improved detection and intervention strategies and robust theories of psychopathology that are informed by modern neuroscientific evidence (Cuthbert et al., 2010; Hyman, 2007).

The RDoC framework (Fig. 1) is implemented in a matrix of rows that correspond to the domains and the constructs within each domain and columns for each of the units of analysis. The cells at the intersections of the rows and columns are populated by elements that have been identified in by prior research findings. The matrix thus provides an integrative summary of evidence linking each level of analysis with the constructs. The domains are limited in number and are not intended to "cover the waterfront" of human behavior, but rather to capture meaningful organizational units that reflect the functions and capacities that the human brain has evolved in order to adaptively serve its evolutionary purposes. Within each domain are constructs for which an implementing neural circuit(s) has been identified and which have a relationship to psychopathology. Thus, each of the domains are based in data about normal functioning and behavior but it is assumed that there is a distribution along the dimension from normal to pathological for each construct. The framework is agnostic with regard to diagnosis; instead, the RDoC heuristic encourages investigators to formulate research questions that are guided by current knowledge about neural circuits and their associated genes, molecules, physiological signals, and behaviors as well as by gaps in that knowledge. This approach encourages interdisciplinary and integrative research as well as novel approaches to the recruitment of study participants. Rather than recruiting participants on the basis of a categorical diagnosis, investigators may want to include participants who do not meet full diagnostic criteria for a disorder or who have symptoms of more than one categorical diagnosis. For example, an investigator might recruit participants from a clinic that serves clients with a variety of psychotic and mood disorders and assess working memory performance or fMRI activation during presentation of rewarding stimuli, and then use this score to arrange the participants along the measured dimension in order to test a hypothesis about a relationship with another RDoC construct or to examine treatment response.
Development and environment are considered to be important dimensions that are orthogonal to the RDoC constructs, and it is anticipated that studies of these important factors will inform the elements that populate the matrix for all of the constructs and at all units of analysis. Although RDoC's two-dimensional matrix precludes the graphical depiction of these dimensions, it is fully expected that these important determinants of human behavior will be incorporated into studies that adopt the RDoC approach. More specifically, for example, neurodevelopmental trajectories and neuroplasticity processes at the synaptic level are appropriate for inclusion in the "circuits" unit of analysis and epigenetic changes resulting from environmental features would be included in the "genes" and "molecules" units of analysis. In this way, future investigations of the constructs and the development of novel interventions will capitalize on improved understanding of developmental and environmental impacts on functioning related to the various domains.

The NIMH RDoC workgroup, consisting of NIMH staff and non-NIMH scientific consultants, has recently finished conducting a series of workshops for the purpose of defining the initial specifications for each of the proposed constructs. Each workshop is focused on a single domain and the participants are investigators from the scientific community with expertise related to the domain who use methodologies that span the various units of analysis. At each workshop, the participants are charged with three tasks: 1) Develop a list of constructs to be included in the domain; 2) Draft a definition for each construct; and 3) Identify the most promising matrix elements for each construct. Following each workshop, a summary of the proceedings is posted on the RDoC website (see below) and ongoing commentary is invited. Concurrently, NIMH has been working to help investigators adopt an RDoCinformed approach to new research projects. Interim guidance for applicants planning to propose studies incorporating the dimensional approach was released in March 2011; a Request for Information to elicit feedback and commentary regarding both general and specific aspects of the RDoC approach was released in May 2011; and two Request for Applications announcements to encourage studies of mechanisms that cut across multiple traditional diagnostic categories and evaluate the construct validity of the RDoC domains were issued by NIMH in August 2011 and in June, 2012. These documents and additional information regarding $\mathrm{RDoC}$ (including the proceedings of 


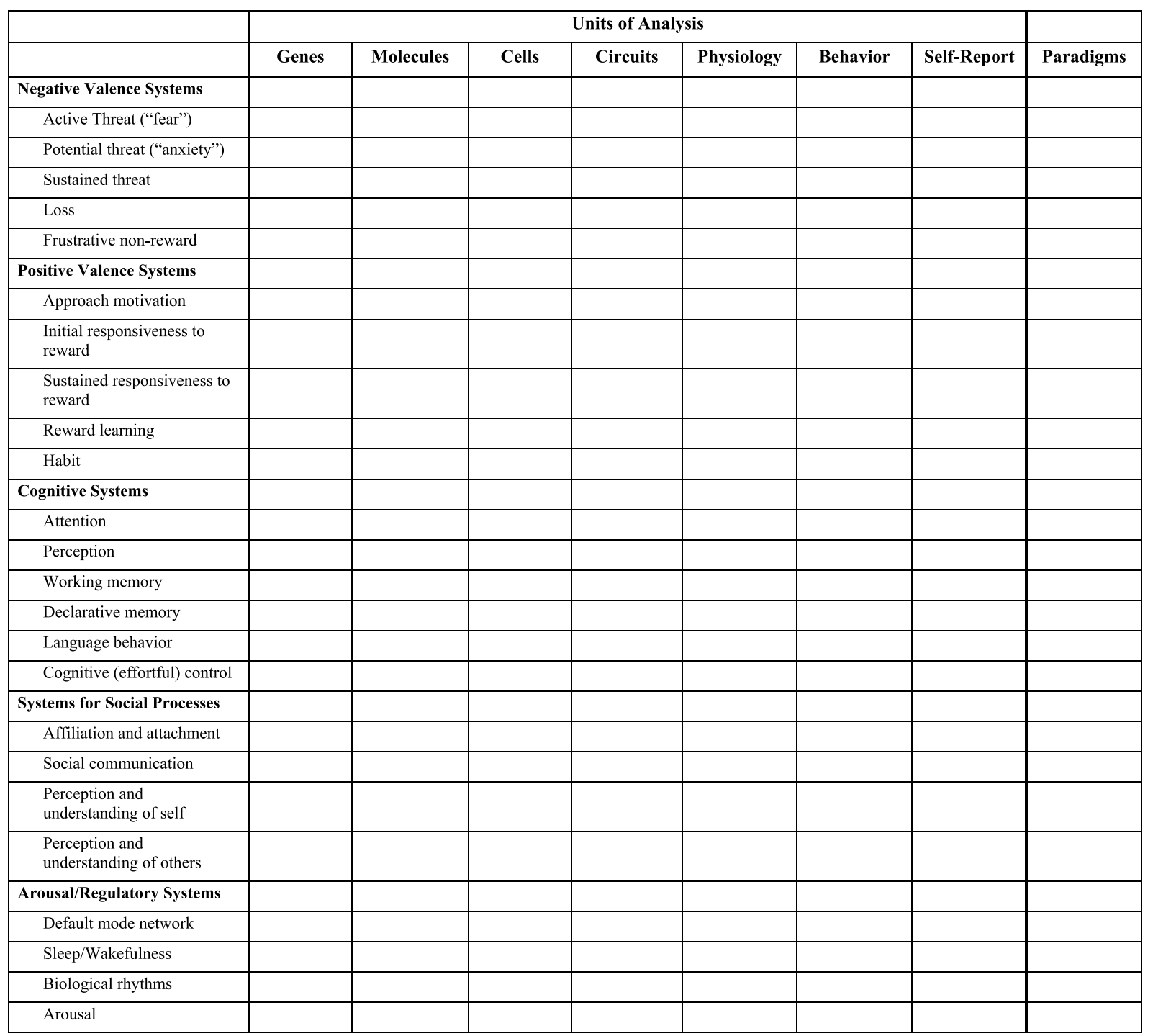

Fig. 1. The draft Research Domain Criteria matrix.

past workshops and draft matrices for each domain) can be viewed at http://www.nimh.nih.gov/researchfunding/rdoc/index.shtml.

The foundations of the RDoC approach have been put in place and ongoing research is needed to examine the validity of the RDoC constructs, elaborate upon the contents of the matrix, and bridge various units of analysis-from genes to molecules and cells to circuits and behavior. Ultimately, the utility of the RDoC approach will be demonstrated by enhancing the efficacy of existing treatments and facilitating the development of novel therapeutics. The construc- tion of the RDoC framework has occurred in tandem with ongoing basic and clinical neuroscience research focused on neural circuits and circuit-based therapeutic approaches. It is anticipated that this research and the $\mathrm{RDoC}$ project will continue to complement and inform each other in an ongoing, synergistic manner.

The dimensional, neuroscience-based approach to nosology reflected in the $\mathrm{RDoC}$ initiative is expected to improve our ability to identify and assess important individual differences as a basis for increasing treatment efficacy and minimizing 
adverse effects. Treatment selection might be based on genetic/genomic profiling (risk genes), symptomatic phenotyping (e.g., anhedonic versus anxious depression), neurocognitive deficits, imaging phenotypes, or a combination of markers (e.g., biosignatures). An enhanced understanding of dysfunctional neural circuits in individual patients (personalized medicine) or in subgroups of patients (precision medicine) will inform treatment development and selection. We expect that effective new treatments will selectively disrupt neuroplastic changes that have resulted in problematic behaviors, and harness the brain's ability to reshape its circuits in response to new experiences, pharmacological agents or other manipulations (Pascual-Leone, 2006).

\section{Intervention research in the RDoC context}

Consistent with the RDoC approach, we expect that a nosology based on an understanding of pathophysiology, mechanisms of treatment response, and the availability of early prognostic markers of treatment response will provide a basis for better target identification and matching of existing approaches to patients. Here, we consider how well-established intervention approaches-psychopharmacology and psychotherapy-might be approached within the RDoC-context and highlight a number of emerging intervention approaches focused at the domain and circuit level.

\section{Psychopharmacology}

Psychopharmacologic treatments have been investigated for their effects at the molecular and circuit levels using a variety of neuroimaging modalities, as well as model animals, but research in humans has been constrained by the focus on conventional DSM categories for which unitary treatment targets are sought. Redefining illness in terms of domains with distinctive neurophysiologies is expected to further target identification for drug development and provide a basis for rational treatment selection.

Schizophrenia, for example, does not present as a homogenous, unitary illness, but rather is comprised of several symptom complexes-psychosis (hallucinations, delusions), cognitive dysfunction, negative symptoms (anhedonia, asociality, alogia) and depressed mood. While antipsychotic medications address the psychosis component, they fail to effectively treat other aspects of the illness. Targeting these varied symptom complexes will broaden the conventional focus on monoamine systems to include other candidate systems (cholinergic, dopaminergic, glutamatergic) for drug development (Ibrahim et al., 2011, 2012) and provide a basis for individualized treatment selection within a single diagnostic category.

A variety of clinical and neurobiological endophenotypes have been identified within schizophrenia, some of which are shared with psychotic bipolar disorder. Resting-state networks, detected with fMRI, show abnormal connections in both schizophrenia and psychotic bipolar illness, some of which are shared across disorders, others of which are unique to each illness (Meda et al., 2012). Within psychosis, schizophrenia and bipolar probands, as well as first degree relatives, show similar cognitive dysfunction involving working and declarative memory, executive function and attention (Ivleva et al., 2012), thus providing a basis for defining neurobiological subtypes for drug development. Treatments developed for shared endophenotypes or symptom complexes may well prove efficacious across disorders.

Similarly, categorical diagnoses of anxiety and depressive disorders are unlikely to be maximally useful for neurobiological investigation, and no single neurotransmitter abnormality (e.g., serotonergic, noradrenergic) is likely to fully explain the constellation of symptoms seen in these disorders. Both anxiety and depression are thought to involve limbic-cortical circuits (prefrontal cortex, subgenual cingulate, hippocampus, amygdala) that impact stress-responsiveness, mood and emotion regulation (Mayberg, 2009; Ressler et al., 2007). In depression, while imaging findings have yielded a general consensus as to the localization of functional changes, the direction of these changes (hypovs. hyper-functioning) has been contradictory. Based on convergent findings in humans and animals, Mayberg (2009) has proposed a circuit model of depression comprised of several widely distributed neural compartments with differential involvement in general behavioral dimensions of sustained mood, motor, cognitive, and circadian dysfunction to capture this complexity. Such dissection of functional neuroanatomy is consistent with RDoC's focus on sampling subjects based on behavioral dimensions and building models that relate these to circuit function. 
In depression, antidepressant medications have been shown to normalize frontal abnormalities, as well as limbic and subcortical abnormalities. Clinical response has been associated with reciprocal limbic-paralimbic and striatal decreases and dorsal cortical increases in glucose metabolism, suggesting a process of neural plasticity or adaptation of brain circuits with chronic treatment (Mayberg, 2009). However, the limited efficacy of antidepressant treatment has fueled efforts to identify pre-treatment predictors of treatment response that might serve to replace a trial-and-error approach to treatment selection. By virtue of its reciprocal connections to cognitive and affective compartments of the mood circuit, the anterior cingulate cortex (ACC) and particularly the rostral ACC (rACC) has been hypothesized to serve as a bridge for the integration of multiple components of affect and cognition and therefore crucial for normalizing the function of the mood circuit (Devinsky et al., 1995; Mayberg, 1997). As first reported by Mayberg et al. (1997), and confirmed by a large number of studies (Pizzagalli, 2011), increased rostral rACC activity has uniquely predicted better antidepressant response across a number of drugs and imaging modalities. Indeed, rACC activation has been shown to predict the magnitude of response as well (Pizzagalli et al., 2001). Such putative biomarkers of integrated circuit functioning and treatment response too may hold value across disorders.

Based on the notion that mental illnesses are themselves disorders of neuroplasticity (Goto et al., 2010), pharmacologic agents that target neuroplasticity or manipulate it in novel ways are of interest (Krystal et al., 2009). When combined with learning-based approaches that are thought to build on experiencedependent forms of neuroplasticity, such medications may act synergistically to enhance their effects. Drugs such as D-cycloserine that facilitate NMDA receptor function have been shown to enhance the effects of extinction/exposure therapy in animals and humans with effects that persist following treatment discontinuation (Norberg et al., 2008). D-cycloserine shows promise as an enhancer in a number of anxiety disorders and may be most useful in those that are particularly refractory to extinction therapies (Ressler et al., 2007). Such drugs may achieve such effects, not through their direct actions, but rather by enhancing neuroplasticity (Norberg et al., 2008). Finally, a better understanding of the neurotrophic and neuroprotective effects of psychotropics, particularly antidepressants and mood stabilizers (Hunsberger et al., 2009; Krys- tal et al., 2009; Sen et al., 2008), may further inform the development pharmacologic-cognitive-behavioral combination therapies.

\section{Evidence-based psychotherapies}

Although a number of evidence-based therapies are emerging, two of the most-established are cognitivebehavior therapy (CBT) and exposure and response prevention, sometimes considered a form of CBT. Cognitive-behavioral therapy (CBT) applies an integrated set of techniques that focus on changing cognition (e.g., automatic dysfunctional thoughts) and behavior (Beck et al., 2011). Specific techniques are adapted to the disorder and the individual, but generally focus on identifying, challenging and restructuring dysfunctional beliefs. In addition to the learning of new behaviors, a goal, particularly in anxiety and addictive disorders, is the extinction of maladaptive behaviors. In anxiety disorders, including obsessive-compulsive disorder (OCD), avoidance of anxiety-provoking stimuli is thought to reinforce maladaptive behaviors. Building on well-developed learning paradigms in both animal and human research, exposure and response prevention entails graded exposures (of increasing intensity) to symptom-evoking stimuli and prevention of the engagement in anxiety-reducing avoidance or compulsive responses, giving the anxiety response time to habituate. Repeated exposures (direct/in vivo, imaginal) result in habituation within and between trials, eventually extinguishing the maladaptive responses (Storch et al., 2009).

While a number of efficacious psychotherapies have been developed, only recently have their neurobiological effects been investigated. Early studies in this area utilized resting-state positron emission tomography (PET) to examine alterations in brain glucose metabolism in response to treatment. An early study in OCD reported a decrease in glucose metabolism in the caudate (a region implicated in OCD by symptom provocation studies) in response to either successful exposure-based therapy or a selective serotonin reuptake inhibitor (SSRI; Baxter et al., 1992). Another study (Schwartz et al., 1996) reported correlations between regions comprising a circuit implicated in OCD-caudate, orbitofrontal and thalamus-which were reduced with either CBT or SSRI treatment, suggesting that these behavioral and pharmacologic interventions act via a common pathway at the circuit 
level. Small studies in pediatric OCD employing magnetic resonance spectroscopy have reported that the SSRI paroxetine reduced glutamate/glutamine concentrations in the caudate (Rosenberg et al., 2000) such effects were not seen in children treated successfully with CBT (Benazon et al., 2003), consistent with the possibility that common circuit-level effects may reflect differences at the molecular level.

Early resting-state metabolic studies in depression yielded less consistent findings, possibly a result of the heterogeneity in symptoms (dysphoric affect, negative emotions, impaired cognition, and anxiety), which implicates several neural systems. Most often these studies identified prefrontal cortex and areas involved in emotion regulation (subgenual cingulate cortex/BA25) and emotional memory formation and retrieval (hippocampus and amygdala) as dysregulated (Ressler et al., 2007). However, both increases and decreases in prefrontal metabolism have been seen with treatment, and both common and unique brain changes have been reported in response to SSRI versus CBT (Goldapple et al., 2004; Linden, 2006). Imaging studies examining the effects of interpersonal psychotherapy and CBT report decreased prefrontal glucose metabolism and blood flow, but with differential, therapy-specific non-frontal effects (Mayberg, 2009). Despite some methodological limitations, these landmark studies strongly suggested that psychotherapy impacts the brain, paving the way for a new generation of sophisticated studies using activation paradigms to examine the effects of treatment on specific circuits.

New research has begun to examine the effects of psychotherapy on emotion regulation, attentional, and reward circuitry using functional magnetic resonance imaging (fMRI) in conjunction with tasks shown to engage specific brain regions and circuits. Behavioral activation therapy for depression, which targets anhedonia (Dichter et al., 2009), has begun to be investigated for its effects on reward circuitry. Mindfulness-based stress reduction (MBSR), which focuses on modifying early attentional processes to create a buffer against emotional reactivity (Chiesa et al., 2009), has been shown to reduce amygdala activity and increase activity in brain regions implicated in attentional deployment in social anxiety disorder, while reducing anxiety and depression symptoms (Goldin et al., 2010).

While these efforts sample their patient populations based on DSM diagnoses, their focus on psychological processes and circuits are expected to provide findings relevant to RDoC's shift toward a dimensional nosology. Dimensional scaling will allow the identification of samples who are at-risk for psychopathology, thus enabling preventive efforts. For example, using a dimensional scale to select healthy volunteers with varying levels of trait anxiety, Indovina et al. (2011) identified two independent neural correlates associated with vulnerability to anxiety (amygdala reactivity, ventral prefrontal responsivity). These investigators suggest that amygdala hyper-reactivity to fear cues may differentially contribute to phobic fear, while both increased amygdala reactivity and impoverished ventral prefrontal cortical recruitment may contribute to generalized anxiety. Such basic neuroscience findings raise the possibility of designing and selecting treatments that differentially target these regions and circuits (e.g., attention vs. emotion regulation training) based on an individual's neural profile, as well as for designing preventive interventions.

Finally, advances in our basic understanding of fear conditioning hold promise for the development of novel therapies, particularly in post-traumatic stress disorder (PTSD) in which fear memory and extinction (new learning involving amygdala and medial prefrontal cortex) are impaired. Once consolidated, a process that requires time, recall restores the memory to a labile state, affording opportunity to promote more adaptive, nonpathological new learning prior to reconsolidation (Johnson, et al., 2012). To take advantage of the reconsolidation process, treatments for pathological fear include repeated exposures, script-driven imagery and guided visualization to reduce the emotional impact of traumatic memories.

\section{Cognitive training}

Cognitive training targets neurocognitive processes and/or neural circuits with the goal of harnessing use-dependent neuroplasticity to achieve durable behavioral improvements. Increasingly, training programs are being designed to address deficits identified using cognitive neuroscience approaches, which draw heavily on components analysis to deconstruct cognitive deficits. Most of these interventions employ adaptive computerized programs that progressively increase difficulty levels as performance improves. Domains targeted have included perceptual processes, attention/vigilance, processing speed, verbal 
and visual learning and memory, working memory, reasoning/problem solving, and social cognition. Training programs vary in their emphasis on "drill and practice," the teaching of explicit strategies versus altering implicit processes, and the goals of compensating for deficits versus restoring impaired neural functions (circuit retraining). A critical issue is the degree to which the benefits of training generalize to untrained tasks or transfer to real-world functioning (Dickinson et al., 2010).

Within psychiatry, this approach has been most widely implemented in schizophrenia, in which it has been shown to improve both cognitive and social functioning with small to moderate effect sizes (McGurk et al., 2007; Wykes et al., 2011). Recent meta-analyses have concluded that functional outcomes are more likely to be improved when cognitive training is combined with psychiatric rehabilitation (McGurk et al., 2007; Wykes et al., 2011). A neuroscience-based protocol utilizing computer-based training, recently implemented in schizophrenia by Vinogradov and colleagues (2012), targets lower-level perceptual processing, working memory and executive processes to increase accuracy, temporal and spatial resolution, and the signal strength of auditory and visual inputs to ultimately increase the efficiency of higher-level cognitive processes. Significant durable gains have been demonstrated at a six-month follow-up on measures of verbal learning/memory, cognitive control, and other measures of cognitive functioning, some of which were related to improved functioning as measured with a quality of life scale (Fisher et al., 2010). Of interest, these improvements were accompanied by increases in serum brain-derived neurotrophic factor (BDNF; Vinogradov et al., 2009a). Negative effects of cholinergic burden were also demonstrated (Vinogradov et al., 2009b). A recent open-label multicenter study (Murthy et al., 2012) replicated improvements on the training tasks, but was unable to demonstrate generalization to performance on an independent cognitive battery or ratings of daily functioning. These contrasting results may be due to differences in methodology, but clearly the discrepant findings highlight the importance of a well-defined and validated training protocol and independent replication prior to large-scale implementation.

Vinogradov and colleagues (Subramaniam et al., 2012) recently examined the effect of their computerized training on another aspect of schizophrenia- that of reality monitoring, conceptualized as a type of source memory that allows one to distinguish internally-versus externally-generated stimuli. Training-induced gains in test performance were correlated with increased fMRI-detected activity of the medial prefrontal cortex (mPFC), a critical node in a network supporting the processing of social-cognitive information. Improvement on the training task was correlated with improvement on other tests of verbal memory and executive functioning, and post-training $\mathrm{mPFC}$ signal was correlated with ratings of social functioning conducted six month later.

Attempts to apply cognitive therapies early in illness course may help stave off the detrimental effects of illness (Jolles et al., 2012). A two-year trial of cognitive enhancement therapy (CET) for early-course schizophrenia, which integrated neurocognitive training with a social-cognitive rehabilitation program, reported moderate effects on cognitive function and strong effects on social cognition and adjustment, as well as on symptoms (Eack et al., 2010). Accompanying these behavioral changes was a greater preservation of gray matter volume in limbic regions, including hippocampus and amygdala.

Given that several cognitive domains are affected across a range of mental disorders, cognitive training holds promise for broad application. One target of relevance is that of working memory, which is impaired in many disorders and predicts performance in many other cognitive tasks. Klingberg (2010) has demonstrated that working memory capacity can be improved by cognitive training and that such improvements are associated with altered functional activity in frontal and parietal regions and basal ganglia. Application of working memory training in attention deficit-hyperactivity disorder (ADHD) has shown positive effects on symptoms of inattention and hyperactivity/impulsivity (Klingberg et al., 2005). Others (e.g., Bar-Haim et al., 2011) have recently extended cognitive training to include affective and attentional biases thought to be key to anxiety and depression. Basic work in identifying circuitry supporting emotion regulation in such disorders (Etkin, 2010) holds promise for extending cognitive training to address regulatory processes traditionally treated with psychotherapies and doing so at an implicit/automatic level (Gyurak et al., 2011).

Critical protocol ingredients remain in need of further attention. These include the optimal timing, duration and spacing of training; the role of motivation and reward; individual differences in neuroplastic 
capacity; and the issue of generalization. Several investigators have stressed the importance of training beyond the stage of rapid behavioral improvements through a slower phase of improvement during which neural reorganization is thought to occur (Karni et al., 1998; Vinogradov et al., 2012). Multicomponent approaches that combine cognitive training with other psychosocial approaches promise to support the transfer and generalization of training (McGurk et al., 2007; Wykes et al., 2011). Combining cognitive training with pharmacologic approaches that seek to increase neuroplasticity and/or noninvasive brain stimulation holds promise for boosting learning and circuit retraining.

\section{Neurofeedback using real-time fMRI}

Advances in neuroimaging and computing have resulted in the ability to provide individuals with realtime feedback on brain activity during fMRI scans that may be used to modulate that activity in a regionallyspecific manner (Cox et al., 1995; deCharms, 2008). Feedback generally targets a region implicated in the pathological process of interest (e.g., anxiety, pain) and is conveyed via a visual representation (e.g., thermometer or gauge) illustrating the degree of activation. Effects of changes in the ability to modulate activity in a region may also be examined for effects on functional connectivity or circuitry more broadly.

Using rtfMRI, De Charms and colleagues have demonstrated that chronic pain patients can learn to control their activation of brain regions such as the rostral ACC (involved in the modulation of pain), leading to a decrease in pain perception (deCharms, 2007, 2008; deCharms et al., 2005; Rainville, 2002). In mental disorders, rtfMRI holds potential for augmenting psychotherapeutic approaches. Preliminary studies in healthy subjects indicate their ability to control brain activation using rtfMRI feedback in limbic regions, including the insula (Caria et al., 2007; Johnston et al., 2010) and amygdala (Johnston et al., 2010) during emotion processing. Thus, rtfMRI offers a means for measuring changes in brain function underlying psychotherapeutic interventions. Future technological advances may make scanners less expensive, smaller and more widely available for use in clinical settings, where they might be used to modulate activity in circuits involved in processes as diverse as emotion regulation, fear and anxiety, and reward processing and to monitor the neural effects of behavioral therapies
(deCharms, 2007, 2008; Hamilton et al., 2011; Ruiz et al., 2011).

\section{Noninvasive brain stimulation}

Stimulation therapies target focal brain regions in order to modulate circuit activity. Transcranial magnetic stimulation (TMS) uses an extracranial magnetic coil to induce current in the cerebral cortex and thus modulate neural activity. The parameters with which it is applied influence the nature and durability of its effects. In general, continuous trains of low frequency $(<1 \mathrm{~Hz})$ repetitive TMS (rTMS) suppress cortical excitability, while intermittent, bursting high frequency $(>1 \mathrm{~Hz})$ rTMS reduces intracortical inhibition (Wagner et al., 2007). Stimulation can be guided by neuroimaging measures to target specific cortical regions (Neggers et al., 2004). Using two scalp electrodes, transcranial direct current stimulation (tDCS) can induce low-amplitude direct currents that penetrate the brain and modify membrane potentials, thus influencing neuronal excitability, but without depolarizing neurons (Wagner et al., 2007). Both techniques can produce effects that endure beyond the period of stimulation (Fregni et al., 2007). A modified TMS coil and conventional MRI scanner can be used to visualize the magnetic field induced by stimulation (Wagner et al., 2007).

Several studies have tested the efficacy of rTMS as a treatment for depression. Prefrontal cortex has been targeted based on the premise of an imbalance in left and right prefrontal activity and limbic structures involved in mood regulation, as well as findings of prefrontal hypometabolism in some patients (George, 2010). A large industry-sponsored trial supporting the efficacy of TMS in treatment-resistant depression resulted in its approval by the U.S. Food and Drug Administration (FDA) as an intervention for treatmentresistant depression in 2008. George (2010) reviewed established protocols and what is known concerning mechanisms of action. Similar to effects seen with electroconvulsive therapy (ECT), TMS can increase monoamine turnover, increase BDNF, and normalize the hypothalamic-pituitary-adrenal (HPA) axis. Recent meta-analyses (Allan et al., 2011; Slotema et al., 2010) have concluded that rTMS is an effective treatment for depression with overall effect sizes in the moderate range.

In schizophrenia, low-frequency rTMS has been used to suppress severe medication-resistant auditory- 
verbal hallucinations (Hoffman et al., 2000, 2005). Overactivity of the left temporoparietal cortex has been associated with auditory hallucinations in schizophrenia. Low-frequency stimulation of temporoparietal cortex has been used experimentally to inhibit cortical excitability in receptive language regions and thereby quell severe treatment-resistant auditory hallucinations with some success (Stanford et al., 2008). Although some studies have been negative (Slotema et al., 2011), several meta-analyses (Aleman et al., 2007; Freitas et al., 2009; Slotema et al., 2010; Tranulis et al., 2008) have concluded that rTMS is more effective than a sham control in treating auditory-verbal hallucinations in schizophrenia.

As with other techniques, much remains to be learned in terms of optimal stimulation parameters (e.g., frequency, laterality, intensity, pulse train duration, interstimulus interval, duration of treatment, durability, and how to identify patients most likely to respond). Intermediate phenotypes for psychiatric diseases and surrogate markers for clinical endpoints may help identify patients most likely to respond. Recent methodological developments include novel stimulation protocols (e.g., theta burst stimulation) and novel coil designs to allow more reliable targeting of deep sites (Harel et al., 2011). Paradigms that seek to manipulate the state of the brain prior to TMS (e.g., through priming or adaptation) may increase its functional resolution. For example, the application of TMS during a cognitive process may preferentially impact the regions involved in that process (Silvanto et al., 2008). Finally, of interest is the possibility that therapies that combine stimulation with other interventions (pharmacology, psychotherapy, cognitive training) may achieve synergistic effects.

\section{Deep brain stimulation}

Applications of modern deep brain stimulation (DBS) in severe, treatment-resistant mental disorders follow on extensive use of this approach in movement disorders, particularly in Parkinson's disease, where effects on emotion were demonstrated. Electrical stimulation is delivered through one or more electrode arrays, generally containing four contacts $(1.27 \mathrm{~mm}$ in diameter, spanning 10-20 mm), implanted through burr holes in the skull into a specific brain region using neuroimaging-guided stereotactic neurosurgical techniques. Placement is generally bilateral. The
DBS leads are connected by subcutaneously-placed wires to one or more implanted pulse generators containing the system battery and microprocessor that drives stimulation. Stimulation parameters can be set and adjusted noninvasively with a handheld computer interface. Although invasive, DBS is nonablative. Stimulation has dynamic effects on neurocircuitry, including regions functionally connected to the site of stimulation. Stimulation can be optimized for the individual patient and modified or discontinued to reverse side effects (Holtzheimer et al., 2011).

Human neuroimaging studies (Mayberg, 2009; Savitz et al., 2009), prior lesioning studies (Leiphart et al., 2010), and to a lesser extent, animal studies (Hamani et al., 2010) have been helpful in identifying targets for stimulation. Imaging studies of depression have most consistently implicated prefrontal cortex, subcallosal cingulate, hippocampus and amygdala as dysregulated. Most DBS studies of depression have stimulated the subcallosal cingulate white matter. Mayberg and colleagues (2005) stimulated this target in a small number of patients with treatment-resistant depression, resulting in significant improvement in four of the six patients at six months. An extension to a larger group of 20 patients (Lozano et al., 2008) reported clinically significant reductions in depression ratings in $55 \%$ of patients at one year, with seven meeting criteria for remission. Responders showed widespread changes in cortical and limbic metabolic activity, involving lateral prefrontal cortex and differential effects in BA25 white matter (increased) and gray matter (reduced). Follow-up data indicated a response rate of nearly $65 \%$ three to six years out (Kennedy et al., 2011). A three-site open-label study of 21 patients targeting the subcallosal cingulate gyrus reported $50 \%$ or greater reductions in symptoms at one month, $48 \%$ at six months and $29 \%$ at 12 months, the latter of which increased to $62 \%$ when using a $40 \%$ reduction in symptoms as the criterion for response (Lozano et al., 2012). Other targets in depression have included the ventral anterior internal capsule (ventral capsule/ventral striatum, VC/VS), where a 53\% response rate was reported at a 24-month $(+/-15$ month) follow-up (Malone et al., 2009) and the nucleus accumbens, where a similar response rate was reported after 12 months (Bewernick et al., 2010). Single case reports have targeted the inferior thalamic peduncle, which connects thalamus and orbitofrontal cortex and is involved in selection attention (Jimenez et al., 2005) and the lateral habenula (Sartorius et al., 2010), 
implicated in reward processing and emotional decision making.

Deep brain stimulation is also being investigated as a nonablative treatment for refractory OCD, thought to involve hyperactivity of fronto-striatalthalamic-cortical circuits (Greenberg et al., 2010). In particular, imaging studies report that the magnitude of orbitofrontal cortical (OFC) activity is proportional to symptom severity and predictive of medication response. The ventral anterior internal capsule (VC/VS) has been most frequent target based on positive experiences with gamma capsulotomy and on functional neuroimaging studies. Benefit has been reported after application of DBS to the VC/VS, more anterior in the internal capsule, the ventral caudate, or the subthalamic nucleus (Greenberg et al., 2010). A recent review reported substantial decreases in symptoms in approximately $50 \%$ of OCD patients studied to date (de Koning et al., 2011). Of interest is the fact that DBS may preferentially affect OCD symptoms selectively, consistent with findings suggesting that different symptom dimensions (e.g., contamination, checking, hoarding, symmetry/completeness) may have at least partially distinctive neural correlates (Greenberg et al., 2010).

Improvement in depression and OCD symptoms progress over months of chronic stimulation and worsen progressively with the termination of stimulation, although metabolic changes linger after chronic stimulation (Greenberg et al., 2010; Holtzheimer et al., 2011). The mechanisms of action include elements of inhibition as well as axonal excitation and depend on the mix of cell bodies and white matter fibers in the location of the stimulation. However, beyond the immediate neural effects, it is likely that behavioral effects result from the gradual modulation of pathological network activity over time (see Holtzheimer et al., 2011 review). Patients are frequently engaged in and continue concomitant treatments (pharmacology, behavioral treatments) that may contribute synergistically to behavioral improvements.

\section{Challenges for the future}

Many challenging and interesting questions related to clinical neuroscience and circuit-based interventions await investigation in future research. In the area of neurogenesis, much of what is known about neurogenesis in adulthood has been derived from studies of non-human mammals, but new technologies hold promise to improve our understanding of these processes in humans (Ming et al., 2011). The question of whether neurogenesis occurs in areas outside of the hippocampus and subventricular zone has been the topic of debate (Gould, 2007) and future studies will determine the extent to which post-natal neocortical neurogenesis plays a role in mental disorders (Boldrini et al., 2009). Regarding neuroplasticity, the extent to which mental disorders result from abnormalities in the processes involved in neuroplasticity (e.g., insufficient, excessive or inappropriate plasticity) or from normal plasticity occurring in the context of abnormallydeveloped circuits is not clear. Increased investigation of this issue will help to guide the development of interventions that capitalize on neuroplasticity to correct or compensate for flawed neural circuits rather than reinforcing maladaptive circuits. In addition, much of our understanding of the principles of neuroplasticity and recovery of function is derived from studies of motor and sensory cortex (Fox, 2009); future work will determine whether such principles apply to other cortical areas and higher-order functions, and whether these are remediable using approaches that are similar to those that have proven effective for neurological disorders. Enhanced understanding of the principles of neuroplasticity may point the way to optimal timing and duration of treatment and novel dosing regimens for pharmacological and behavioral interventions (Castner et al., 2007; Krystal, 2007; Krystal et al., 2009). Finally, researchers have only just begun to explore the complexity of epigenetic processes as they relate to behavior and mental disorders. Future work will address unanswered questions about the factors that impact the stability and heritability of epigenetic modifications, their relationships to mental disorders, and the ways in which epigenetic processes might be harnessed for therapeutic purposes.

Progressing beyond models of mental disorders that are based on symptom reports or involve broad ideas about "chemical imbalance" to paradigms that involve measuring and modifying neural circuits presents new challenges and opportunities. For example, rapidlyemerging optogenetic methods hold promise for studying neural circuit function in behaving animals with previously unattainable temporal and spatial specificity (Tye et al., 2012). This approach is already starting to yield insights that will enhance our understanding of the role of plasticity-related mechanisms in illness and treatment (Yizhar et al., 2011). New 
methods of measuring changes in brain structure and function using neuroimaging and electrophysiological techniques (e.g., Maris et al., 2011; Zatorre et al., 2012) can be used both to individualize treatment and to evaluate outcomes. These measures may be more sensitive than behavioral or symptom measures and may help in identifying treatment mechanisms and in evaluating outcomes. Eventually, in keeping with the goals of the RDoC project, such neural-systems assessments may become the basis for new entirely new approaches to the nosology of mental disorders.

\section{Conclusion}

The challenges of explicating the multitude of synergistic, additive, and differential genetic, environment, and developmental effects that contribute to mental disorders are daunting. Fortunately, new tools and perspectives are rapidly developing that can assist in this effort. As reviewed in this paper, innovative findings about mechanisms of brain development and plasticity are beginning to help us understand how genetic endowment is sculpted by experience to result in particular patterns of function (and dysfunction). Such a push to move past broad phenotypes toward more specific understanding of particular mechanisms (i.e., "precision medicine") characterizes all areas of current biomedical research, and is beginning to take root in the study of mental illness. With progress in formulating and evaluating novel hypotheses that capture the nervous system's complexity, there is good reason for optimism that treatments for mental disorders will soon benefit from the burgeoning pace of new discoveries.

\section{Disclaimer}

The views herein do not necessarily represent the official views of the National Institute of Mental Health, the National Institutes of Health, the U.S. Department of Health and Human Services, or any other agency of the United States Government.

\section{References}

Aleman, A., Sommer, I.E. \& Kahn, R.S. (2007). Efficacy of slow repetitive transcranial magnetic stimulation in the treatment of resistant auditory hallucinations in schizophrenia: A metaanalysis. J Clin Psychiatry, 68(3), 416-421.
Allan, C.L., Herrmann, L.L. \& Ebmeier, K.P. (2011). Transcranial magnetic stimulation in the management of mood disorders. Neuropsychobiology, 64(3), 163-169.

Allen, N.D. (2008). Temporal and epigenetic regulation of neurodevelopmental plasticity. Phil Trans $R$ Soc B, 363(1489), 23-38.

Ayalew, M., Le-Niculescu, H., Levey, D.F., Jain, N., Changala, B., Patel, S.D., Winiger, E., Breier, A., Shekhar, A., Amdur, R., Koller, D., Nurnberger, J.I., Corvin, A., Geyer, M., Tsuang, M.T., Salomon, D., Schork, N.J., Fanous, A.H., O’Donovan, M.C. \& Niculescu, A.B. (2012). Convergent functional genomics of schizophrenia: From comprehensive understanding to genetic risk prediction. Mol Psychiatry, 17, 887-905.

Balu, D.T. \& Coyle, J.T. (2011). Neuroplasticity signaling pathways linked to the pathophysiology of schizophrenia. Neurosci Biobehav Rev, 35(3), 848-870.

Balu, D.T. \& Lucki, I. (2009). Adult hippocampal neurogenesis: Regulation, functional implications, and contribution to disease pathology. Neurosci Biobehav Rev, 33(3), 232-252.

Bar-Haim, Y., Morag, I. \& Glickman, S. (2011). Training anxious children to disengage attention from threat: A randomized controlled trial. J Child Psychol Psychiatry, 52(8), 861-869.

Baxter, L.R., Jr Schwartz, J.M., Bergman, K.S., Szuba, M.P., Guze, B.H., Mazziotta, J.C., Alazraki, A., Selin, C.E., Ferng, H.K. \& Munford, P. et al. (1992). Caudate glucose metabolic rate changes with both drug and behavior therapy for obsessivecompulsive disorder. Arch Gen Psychiatry, 49(9), 681-689.

Beck, A.T. \& Dozois, D.J. (2011). Cognitive therapy: Current status and future directions. Annu Rev Med, 62, 397-409.

Benazon, N.R., Moore, G.J. \& Rosenberg, D.R. (2003). Neurochemical analyses in pediatric obsessive-compulsive disorder in patients treated with cognitive-behavioral therapy. J Am Acad Child Adolesc Psychiatry, 42(11), 1279-1285.

Bewernick, B.H., Hurlemann, R., Matusch, A., Kayser, S., Grubert, C., Hadrysiewicz, B., Axmacher, N., Lemke, M., CooperMahkorn, D., Cohen, M.X., Brockmann, H., Lenartz, D., Sturm, V. \& Schlaepfer, T.E. (2010). Nucleus accumbens deep brain stimulation decreases ratings of depression and anxiety in treatment-resistant depression. Biol Psychiatry, 67(2), 110-116.

Boldrini, M., Underwood, M.D., Hen, R., Rosoklija, G.B., Dwork, A.J., John Mann, J. \& Arango, V. (2009). Antidepressants increase neural progenitor cells in the human hippocampus. Neuropsychopharmacology, 34(11), 2376-2389.

Buonanno, A. (2010). The neuregulin signaling pathway and schizophrenia: From genes to synapses and neural circuits. Brain Res Bull, 83(3-4), 122-131.

Caria, A., Veit, R., Sitaram, R., Lotze, M., Weiskopf, N., Grodd, W. \& Birbaumer, N. (2007). Regulation of anterior insular cortex activity using real-time fMRI. NeuroImage, 35(3), 1238-1246.

Castner, S.A. \& Williams, G.V. (2007). From vice to virtue: Insights from sensitization in the nonhuman primate. Prog Neuropsychopharmacol Biol Psychiatry, 31(8), 1572-1592.

Chiesa, A. \& Serretti, A. (2009). Mindfulness-based stress reduction for stress management in healthy people: A review and metaanalysis. J Altern Complement Med, 15(5), 593-600.

Couillard-Despres, S., Vreys, R., Aigner, L. \& Van Der Linden, A. (2011). In vivo monitoring of adult neurogenesis in health and disease. Front Neurosci, 5(67), doi: 10.3389/fnins.2011.00067 
Cox, R.W., Jesmanowicz, A. \& Hyde, J.S. (1995). Real-time functional magnetic resonance imaging. Magn Reson Med, 33(2), 230-236.

Cramer, S.C., Sur, M., Dobkin, B.H., O’Brien, C., Sanger, T.D., Trojanowski, J.Q., Rumsey, J.M., Hicks, R., Cameron, J., Chen, D., Chen, W.G., Cohen, L.G., deCharms, C., Duffy, C.J., Eden, G.F., Fetz, E.E., Filart, R., Freund, M., Grant, S.J., Haber, S., Kalivas, P.W., Kolb, B., Kramer, A.F., Lynch, M., Mayberg, H.S., McQuillen, P.S., Nitkin, R., Pascual-Leone, A., ReuterLorenz, P., Schiff, N., Sharma, A., Shekim, L., Stryker, M., Sullivan, E.V. \& Vinogradov, S. (2011). Harnessing neuroplasticity for clinical applications. Brain, 134(6), 1591-1609.

Cuthbert, B.N. \& Insel, T.R. (2010). Toward new approaches to psychotic disorders: The NIMH research domain criteria project. Schizophr Bull, 36(6), 1061-1062.

de Koning, P.P., Figee, M., van den Munckhof, P., Schuurman, P.R. \& Denys, D. (2011). Current status of deep brain stimulation for obsessive-compulsive disorder: A clinical review of different targets. Curr Psychiatry Rep, 13(4), 274-282.

deCharms, R.C. (2007). Reading and controlling human brain activation using real-time functional magnetic resonance imaging. Trends Cogn Sci, 11(11), 473-481.

deCharms, R.C. (2008). Applications of real-time fMRI. Nat Rev Neurosci, 9(9), 720-729.

deCharms, R.C., Maeda, F., Glover, G.H., Ludlow, D., Pauly, J.M., Soneji, D., Gabrieli, J.D. \& Mackey, S.C. (2005). Control over brain activation and pain learned by using real-time functional mri. Proc Natl Acad Sci U S A, 102(51), 18626-18631.

Devinsky, O., Morrell, M.J. \& Vogt, B.A. (1995). Contributions of anterior cingulate cortex to behaviour. Brain, 118(Pt 1), 279306

Dichter, G.S., Felder, J.N., Petty, C., Bizzell, J., Ernst, M. \& Smoski, M.J. (2009). The effects of psychotherapy on neural responses to rewards in major depression. Biol Psychiatry, 66(9), 886-897.

Dickinson, D., Tenhula, W., Morris, S., Brown, C., Peer, J., Spencer, K., Li, L., Gold, J.M. \& Bellack, A.S. (2010). A randomized, controlled trial of computer-assisted cognitive remediation for schizophrenia. Am J Psychiatry, 167(2), 170-180.

Drevets, W.C. (2004). Neuroplasticity in mood disorders. Dialogues Clin Neurosci, 6(2), 199-216.

Duan, X., Kang, E., Liu, C.Y., Ming, G.-1. \& Song, H. (2008). Development of neural stem cell in the adult brain. Curr Opin Neurobiol, 18(1), 108-115.

Dulac, C. (2010). Brain function and chromatin plasticity. Nature, 465(7299), 728-735.

Eack, S.M., Hogarty, G.E., Cho, R.Y., Prasad, K.M.R., Greenwald, D.P., Hogarty, S.S. \& Keshavan, M.S. (2010). Neuroprotective effects of cognitive enhancement therapy against gray matter loss in early schizophrenia results from a 2-year randomized controlled trial. Arch Gen Psychiatry, 67(7), 674-682.

Eisch, A.J., Cameron, H.A., Encinas, J.M., Meltzer, L.A., Ming, G.-L. \& Overstreet-Wadiche, L.S. (2008). Adult neurogenesis. mental health, and mental illness: Hope or hype? J Neurosci, 28(46), 11785-11791.

Etkin, A. (2010). Functional neuroanatomy of anxiety: A neural circuit perspective. Curr Top Behav Neurosci, 2, 251-277.
Feil, R. (2008). Epigenetics, an emerging discipline with broad implications. C R Biol, 331(11), 837-843.

Fisher, M., Holland, C., Subramaniam, K. \& Vinogradov, S. (2010). Neuroplasticity-based cognitive training in schizophrenia: An interim report on the effects 6 months later. Schizophr Bull, 36(4), 869-879.

Fox, K. (2009). Experience-dependent plasticity mechanisms for neural rehabilitation in somatosensory cortex. Phil Trans $R$ Soc $B, 364(1515), 369-381$.

Fregni, F. \& Pascual-Leone, A. (2007). Technology insight: Noninvasive brain stimulation in neurology-perspectives on the therapeutic potential of rTMS and tdcs. Nat Clin Pract Neurol, 3(7), 383-393.

Freitas, C., Fregni, F. \& Pascual-Leone, A. (2009). Meta-analysis of the effects of repetitive transcranial magnetic stimulation (rTMS) on negative and positive symptoms in schizophrenia. Schizophr Res, 108(1-3), 11-24.

Gallinat, J., Bauer, M. \& Heinz, A. (2008). Genes and neuroimaging: Advances in psychiatric research. Neurodegener Dis, 5(5), 277 285 .

Gentili, R., Han, C.E., Schweighofer, N. \& Papaxanthis, C. (2010). Motor learning without doing: Trial-by-trial improvement in motor performance during mental training. J Neurophysiol, 104(2), 774-783.

George, M.S. (2010). Transcranial magnetic stimulation for the treatment of depression. Expert Rev Neurother, 10(11), 1761-1772.

Goldapple, K., Segal, Z., Garson, C., Lau, M., Bieling, P., Kennedy, S. \& Mayberg, H. (2004). Modulation of cortical-limbic pathways in major depression: Treatment-specific effects of cognitive behavior therapy. Arch Gen Psychiatry, 61(1), 34-41.

Goldin, P.R. \& Gross, J.J. (2010). Effects of mindfulness-based stress reduction (mbsr) on emotion regulation in social anxiety disorder. Emotion, 10(1), 83-91.

Goto, Y., Yang, C.R. \& Otani, S. (2010). Functional and dysfunctional synaptic plasticity in prefrontal cortex: Roles in psychiatric disorders. Biol Psychiatry, 67(3), 199-207.

Gould, E. (2007). How widespread is adult neurogenesis in mammals? Nat Rev Neurosci, 8(6), 481-488.

Greenberg, B.D., Rauch, S.L. \& Haber, S.N. (2010). Invasive circuitry-based neurotherapeutics: Stereotactic ablation and deep brain stimulation for OCD. Neuropsychopharmacology, $35(1), 317-336$

Guy, J., Gan, J., Selfridge, J., Cobb, S. \& Bird, A. (2007). Reversal of neurological defects in a mouse model of rett syndrome. Science, 315(5815), 1143-1147.

Gyurak, A., Gross, J.J. \& Etkin, A. (2011). Explicit and implicit emotion regulation: A dual-process framework. Cogn Emot, 25(3), 400-412.

Hamani, C. \& Nobrega, J.N. (2010). Deep brain stimulation in clinical trials and animal models of depression. Eur J Neurosci, 32(7), 1109-1117.

Hamilton, J.P., Glover, G.H., Hsu, J.J., Johnson, R.F. \& Gotlib, I.H. (2011). Modulation of subgenual anterior cingulate cortex activity with real-time neurofeedback. Hum Brain Mapp, 32(1), 22-31 
Harel, E.V., Zangen, A., Roth, Y., Reti, I., Braw, Y. \& Levkovitz, Y. (2011). H-coil repetitive transcranial magnetic stimulation for the treatment of bipolar depression: An add-on, safety and feasibility study. World J Biol Psychiatry, 12(2), 119-126.

Hoffman, R.E., Boutros, N.N., Hu, S., Berman, R.M., Krystal, J.H. \& Charney, D.S. (2000). Transcranial magnetic stimulation and auditory hallucinations in schizophrenia. Lancet, 355(9209), 1073-1075.

Hoffman, R.E., Gueorguieva, R., Hawkins, K.A., Varanko, M., Boutros, N.N., Wu, Y.T., Carroll, K. \& Krystal, J.H. (2005). Temporoparietal transcranial magnetic stimulation for auditory hallucinations: Safety, efficacy and moderators in a fifty patient sample. Biol Psychiatry, 58(2), 97-104.

Holtzheimer, P.E. \& Mayberg, H.S. (2011). Deep brain stimulation for psychiatric disorders. Annu Rev Neurosci, 34, 289307.

Hsieh, J. \& Eisch, A.J. (2010). Epigenetics, hippocampal neurogenesis, and neuropsychiatric disorders: Unraveling the genome to understand the mind. Neurobiol Dis, 39(1), 73-84.

Hunsberger, J., Austin, D.R., Henter, I.D. \& Chen, G. (2009) The neurotrophic and neuroprotective effects of psychotropic agents. Dialogues Clin Neurosci, 11(3), 333-348.

Hyman, S.E. (2007). Can neuroscience be integrated into the DSMV? Nat Rev Neurosci, 8(9), 725-732.

Ibrahim, H.M. \& Tamminga, C.A. (2011). Schizophrenia: Treatment targets beyond monoamine systems. Annu Rev Pharmacol Toxicol, 51, 189-209.

Ibrahim, H.M. \& Tamminga, C.A. (2012). Treating impaired cognition in schizophrenia. Curr Pharm Biotechnol, 13(8), $1587-1594$

Indovina, I., Robbins, T.W., Nunez-Elizalde, A.O., Dunn, B.D. \& Bishop, S.J. (2011). Fear-conditioning mechanisms associated with trait vulnerability to anxiety in humans. Neuron, 69(3), 563-571.

Ishizuka, K., Paek, M., Kamiya, A. \& Sawa, A. (2006). A review of disrupted-in-schizophrenia-1 (DISC1): Neurodevelopment, cognition, and mental conditions. Biological Psychiatry, 59(12), 1189-1197.

Ivleva, E.I., Morris, D.W., Osuji, J., Moates, A.F., Carmody, T.J., Thaker, G.K., Cullum, M. \& Tamminga, C.A. (2012). Cognitive endophenotypes of psychosis within dimension and diagnosis. Psychiatry Res, 196(1), 38-44.

Jimenez, F., Velasco, F., Salin-Pascual, R., Hernandez, J.A., Velasco, M., Criales, J.L. \& Nicolini, H. (2005). A patient with a resistant major depression disorder treated with deep brain stimulation in the inferior thalamic peduncle. Neurosurgery, 57(3), 585-593. discussion 585-593.

Johnston, S.J., Boehm, S.G., Healy, D., Goebel, R. \& Linden, D.E. (2010). Neurofeedback: A promising tool for the self-regulation of emotion networks. NeuroImage, 49(1), 1066-1072.

Johnson, L.R., McGuire, J., Lazarus, R. \& Palmer, A.A. (2012). Pavlovian fear memory circuits and phenotype models of PTSD. Neuropharmacol, 62(2), 638-646.

Jolles, D. \& Crone, E.A. (2012). Training the developing brain A neurocognitive perspective. Front Hum Neurosci, 6(76), 10.3389 /fnhum.2012.00076.
Kang, E., Burdick, Katherine, E., Kim, Ju, Y., Duan, X., Guo, Junjie, U., Sailor Kurt, A., Jung, D.-E., Ganesan, S., Choi, S., Pradhan, D., Lu, B., Avramopoulos, D., Christian, K., Malhotra, Anil, K., Song, H. \& Ming, G-1 (2011). Interaction between FEZ1 and DISC1 in regulation of neuronal development and risk for schizophrenia. Neuron, 72(4), 559-571.

Karni, A., Meyer, G., Rey-Hipolito, C., Jezzard, P., Adams, M.M., Turner, R. \& Ungerleider, L.G. (1998). The acquisition of skilled motor performance: Fast and slow experience-driven changes in primary motor cortex. Proc Natl Acad Sci U S A, 95(3), 861-868.

Kennedy, S.H., Giacobbe, P., Rizvi, S.J., Placenza, F.M., Nishikawa, Y., Mayberg, H.S. \& Lozano, A.M. (2011). Deep brain stimulation for treatment-resistant depression: Follow-up after 3 to 6 years. Am J Psychiatry, 168(5), 502-510.

Klingberg, T. (2010). Training and plasticity of working memory. Trends Cogn Sci, 14(7), 317-324.

Klingberg, T., Fernell, E., Olesen, P.J., Johnson, M., Gustafsson, P., Dahlstrom, K., Gillberg, C.G., Forssberg, H. \& Westerberg, H. (2005). Computerized training of working memory in children with ADHD-a randomized, controlled trial. J Am Acad Child Adolesc Psychiatry, 44(2), 177-186.

Koob, G.F. \& Volkow, N.D. (2009). Neurocircuitry of addiction. Neuropsychopharmacology, 35(1), 217-238.

Krystal, J.H. (2007). Neuroplasticity as a target for the pharmacotherapy of psychiatric disorders: New opportunities for synergy with psychotherapy. Biol Psychiatry, 62(8), 833834.

Krystal, J.H., Tolin, D.F., Sanacora, G., Castner, S.A., Williams, G.V., Aikins, D.E., Hoffman, R.E. \& D’Souza, D.C. (2009). Neuroplasticity as a target for the pharmacotherapy of anxiety disorders, mood disorders, and schizophrenia. Drug Discov Today, 14(13-14), 690-697.

Leiphart, J.W. \& Valone, F.H. (3rd). (2010). Stereotactic lesions for the treatment of psychiatric disorders. J Neurosurg, 113(6), 1204-1211.

Lewis, D.A. \& Gonzalez-Burgos, G. (2007). Neuroplasticity of neocortical circuits in schizophrenia. Neuropsychopharmacology, $33(1), 141-165$

Linden, D.E. (2006). How psychotherapy changes the brain-the contribution of functional neuroimaging. Mol Psychiatry, 11(6), 528-538.

Lozano, A.M., Giacobbe, P., Hamani, C., Rizvi, S.J., Kennedy, S.H., Kolivakis, T.T., Debonnel, G., Sadikot, A.F., Lam, R.W., Howard, A.K., Ilcewicz-Klimek, M., Honey, C.R. \& Mayberg, H.S. (2012). A multicenter pilot study of subcallosal cingulate area deep brain stimulation for treatment-resistant depression. J Neurosurg, 116(2), 315-322.

Lozano, A.M., Mayberg, H.S., Giacobbe, P., Hamani, C., Craddock, R.C. \& Kennedy, S.H. (2008). Subcallosal cingulate gyrus deep brain stimulation for treatment-resistant depression. Biol Psychiatry, 64(6), 461-467.

Malone, D.A., Jr., Dougherty, D.D., Rezai, A.R., Carpenter, L.L., Friehs, G.M., Eskandar, E.N., Rauch, S.L., Rasmussen, S.A., Machado, A.G., Kubu, C.S., Tyrka, A.R., Price, L.H., Stypulkowski, P.H., Giftakis, J.E., Rise, M.T., Malloy, P.F., Salloway, S.P. \& Greenberg, B.D. (2009). Deep brain stimulation 
of the ventral capsule/ventral striatum for treatment-resistant depression. Biol Psychiatry, 65(4), 267-275.

Maris, E., van Vugt, M. \& Kahana, M. (2011). Spatially distributed patterns of oscillatory coupling between high-frequency amplitudes and low-frequency phases in human ieeg. NeuroImage, 54(2), 836-850.

Markram, K., Rinaldi, T., Mendola, D.L., Sandi, C. \& Markram, H. (2007). Abnormal fear conditioning and amygdala processing in an animal model of autism. Neuropsychopharmacology, 33(4), 901-912.

Mateus-Pinheiro, A., Pinto, L. \& Sousa, N. (2011). Epigenetic (de)regulation of adult hippocampal neurogenesis: Implications for depression. Clinical Epigenetics, 3(1), 5-17.

Matrisciano, F., Tueting, P., Dalal, I., Kadriu, B., Grayson, D.R., Davis, J.M., Nicoletti, F. \& Guidotti, A. (2012). Epigenetic modifications of gabaergic interneurons are associated with the schizophrenia-like phenotype induced by prenatal stress in mice. Neuropharmacology (epub ahead of print).

Mayberg, H.S. (1997). Limbic-cortical dysregulation: A proposed model of depression. J Neuropsychiatry Clin Neurosci, 9(3), 471-481.

Mayberg, H.S. (2009). Targeted electrode-based modulation of neural circuits for depression. J Clin Invest, 119(4), 717-725.

Mayberg, H.S., Lozano, A.M., Voon, V., McNeely, H.E., Seminowicz, D., Hamani, C., Schwalb, J.M. \& Kennedy, S.H. (2005). Deep brain stimulation for treatment-resistant depression. $\mathrm{Neu}$ ron, 45(5), 651-660

McGowan, P.O., Sasaki, A., D’Alessio, A.C., Dymov, S., Labonte, B., Szyf, M., Turecki, G. \& Meaney, M.J. (2009). Epigenetic regulation of the glucocorticoid receptor in human brain associates with childhood abuse. Nat Neurosci, 12(3), 342-348.

McGurk, S.R., Twamley, E.W., Sitzer, D.I., McHugo, G.J. \& Mueser, K.T. (2007). A meta-analysis of cognitive remediation in schizophrenia. Am J Psychiatry, 164(12), 1791-1802.

Meaney, M.J. (2010). Epigenetics and the biological definition of gene $\times$ environment interactions. Child Dev, 81(1), 41-79.

Meda, S.A., Gill, A., Stevens, M.C., Lorenzoni, R.P., Glahn, D.C., Calhoun, V.D., Sweeney, J.A., Tamminga, C.A., Keshavan, M.S., Thaker, G. \& Pearlson, G.D. (2012). Differences in resting-state functional magnetic resonance imaging functional network connectivity between schizophrenia and psychotic bipolar probands and their unaffected first-degree relatives. Biol Psychiatry, 71(10), 881-889.

Mehler, M.F. (2008a). Epigenetic principles and mechanisms underlying nervous system functions in health and disease. Prog Neurobiol, 86(4), 305-341.

Mehler, M.F. (2008b). Epigenetics and the nervous system. Ann Neurol, 64(6), 602-617.

Meyer-Lindenberg, A. \& Tost, H. (2012). Neural mechanisms of social risk for psychiatric disorders. Nat Neurosci, 15(5), 663668.

Mill, J., Tang, T., Kaminsky, Z., Khare, T., Yazdanpanah, S., Bouchard, L., Jia, P., Assadzadeh, A., Flanagan, J., Schumacher, A., Wang, S.-C. \& Petronis, A. (2008). Epigenomic profiling reveals DNA-methylation changes associated with major psychosis. Am J Hum Genet, 82(3), 696-711.
Ming, G.-1. \& Song, H. (2011). Adult neurogenesis in the mammalian brain: Significant answers and significant questions. Neuron, 70(4), 687-702.

Murthy, N.V., Mahncke, H., Wexler, B.E., Maruff, P., Inamdar, A., Zucchetto, M., Lund, J., Shabbir, S., Shergill, S., Keshavan, M., Kapur, S., Laruelle, M. \& Alexander, R. (2012). Computerized cognitive remediation training for schizophrenia: An open label, multi-site, multinational methodology study. Schizophr Res, 139(1-3), 87-91.

National Institute of Mental Health. (2008). The National Institute of Mental Health Strategic Plan. Bethesda, MD: National Institute of Mental Health (NIH Publication 08-6368; http://www.nimh.nih.gov/about/strategic-planningreports/index.shtml).

Neggers, S.F., Langerak, T.R., Schutter, D.J., Mandl, R.C., Ramsey, N.F., Lemmens, P.J. \& Postma, A. (2004). A stereotactic method for image-guided transcranial magnetic stimulation validated with fMRI and motor-evoked potentials. NeuroImage, 21(4), 1805-1817.

Niwa, M., Kamiya, A., Murai, R., Kubo, K.-I., Gruber, A.J., Tomita, K., Lu, L., Tomisato, S., Jaaro-Peled, H., Seshadri, S., Hiyama, H., Huang, B., Kohda, K., Noda, Y., O’Donnell, P., Nakajima, K., Sawa, A. \& Nabeshima, T. (2010). Knockdown of DISC1 by in utero gene transfer disturbs postnatal dopaminergic maturation in the frontal cortex and leads to adult behavioral deficits. Neuron, 65(4), 480-489.

Norberg, M.M., Krystal, J.H. \& Tolin, D.F. (2008). A meta-analysis of D-cycloserine and the facilitation of fear extinction and exposure therapy. Biol Psychiatry, 63(12), 1118-1126.

Pantelis, C., Yücel, M., Wood, S.J., Velakoulis, D., Sun, D., Berger, G., Stuart, G.W., Yung, A., Phillips, L. \& McGorry, P.D. (2005). Structural brain imaging evidence for multiple pathological processes at different stages of brain development in schizophrenia. Schizophrenia Bull, 31(3), 672-696.

Pascual-Leone, A. (2006). Disrupting the brain to guide plasticity and improve behavior. In R. M. Aage (Ed.), Progress in Brain Research (Vol. 157, pp. 315-404): Elsevier.

Pascual-Leone, A., Amedi, A., Fregni, F. \& Merabet, L.B. (2005). The plastic human brain cortex. Annu Rev Neurosci, 28(1), 377401.

Phillips, M.L., Ladouceur, C.D. \& Drevets, W.C. (2008). A neural model of voluntary and automatic emotion regulation: Implications for understanding the pathophysiology and neurodevelopment of bipolar disorder. Mol Psychiatry, 13(9), 833-857.

Pidsley, R. \& Mill, J. (2011). Epigenetic studies of psychosis: Current findings, methodological approaches, and implications for postmortem research. Biol Psychiatry, 69(2), 146-156.

Pittenger, C. \& Duman, R.S. (2007). Stress, depression, and neuroplasticity: A convergence of mechanisms. Neuropsychopharmacology, 33(1), 88-109.

Pizzagalli, D., Pascual-Marqui, R.D., Nitschke, J.B., Oakes, T.R., Larson, C.L., Abercrombie, H.C., Schaefer, S.M., Koger, J.V., Benca, R.M. \& Davidson, R.J. (2001). Anterior cingulate activity as a predictor of degree of treatment response in major depression: Evidence from brain electrical tomography analysis. Am J Psychiatry, 158(3), 405-415. 
Pizzagalli, D.A. (2011). Frontocingulate dysfunction in depression: Toward biomarkers of treatment response. Neuropsychopharmacology, 36(1), 183-206.

Post, R.M. (2007). Kindling and sensitization as models for affective episode recurrence, cyclicity, and tolerance phenomena. Neurosci Biobehav Rev, 31(6), 858-873.

Rainville, P. (2002). Brain mechanisms of pain affect and pain modulation. Curr Opin Neurobiol, 12, 195-204.

Rapoport, J.L., Addington, A.M., Frangou, S. \& Psych, M.R.C. (2005). The neurodevelopmental model of schizophrenia: Update 2005. Mol Psychiatry, 10(5), 434-449.

Reif, A., Fritzen, S., Finger, M., Strobel, A., Lauer, M., Schmitt, A. \& Lesch, K.P. (2006). Neural stem cell proliferation is decreased in schizophrenia, but not in depression. Mol Psychiatry, 11(5), 514-522.

Ressler, K.J. \& Mayberg, H.S. (2007). Targeting abnormal neural circuits in mood and anxiety disorders: From the laboratory to the clinic. Nat Neurosci, 10(9), 1116-1124.

Richards, E.J. (2006). Inherited epigenetic variation - revisiting soft inheritance. Nat Rev Genet, 7(5), 395-401.

Robinson, L., Guy, J., McKay, L., Brockett, E., Spike, R.C., Selfridge, J., De Sousa, D., Merusi, C., Riedel, G., Bird, A. \& Cobb, S.R. (2012). Morphological and functional reversal of phenotypes in a mouse model of rett syndrome. Brain, 135, 2699-2710.

Rosenberg, D.R., MacMaster, F.P., Keshavan, M.S., Fitzgerald, K.D., Stewart, C.M. \& Moore, G.J. (2000). Decrease in caudate glutamatergic concentrations in pediatric obsessive-compulsive disorder patients taking paroxetine. J Am Acad Child Adolesc Psychiatry, 39(9), 1096-1103.

Ruiz, S., Lee, S., Soekadar, S.R., Caria, A., Veit, R., Kircher, T., Birbaumer, N. \& Sitaram, R. (2011). Acquired self-control of insula cortex modulates emotion recognition and brain network connectivity in schizophrenia. Hum Brain Mapp (epub ahead of print).

Sartorius, A., Kiening, K.L., Kirsch, P., von Gall, C.C., Haberkorn, U., Unterberg, A.W., Henn, F.A. \& Meyer-Lindenberg, A. (2010). Remission of major depression under deep brain stimulation of the lateral habenula in a therapy-refractory patient. Biol Psychiatry, 67(2), e9-e11.

Savitz, J.B. \& Drevets, W.C. (2009). Imaging phenotypes of major depressive disorder: Genetic correlates. Neuroscience, 164(1), 300-330.

Schloesser, R.J., Huang, J., Klein, P.S. \& Manji, H.K. (2007). Cellular plasticity cascades in the pathophysiology and treatment of bipolar disorder. Neuropsychopharmacology, 33(1), 110133.

Schwartz, J.M., Stoessel, P.W., Baxter, L.R., Jr. Martin, K.M. \& Phelps, M.E. (1996). Systematic changes in cerebral glucose metabolic rate after successful behavior modification treatment of obsessive-compulsive disorder. Arch Gen Psychiatry, 53(2), 109-113.

Sen, S., Duman, R. \& Sanacora, G. (2008). Serum brain-derived neurotrophic factor, depression, and antidepressant medications: Meta-analyses and implications. Biol Psychiatry, 64(6), $527-$ 532.
Silvanto, J., Muggleton, N. \& Walsh, V. (2008). State-dependency in brain stimulation studies of perception and cognition. Trends Cogn Sci, 12(12), 447-454.

Slotema, C.W., Blorn, J.D., de Weijer, A.D., Diederen, K.M., Goekoop, R., Looljestin, J., Daalman, K., Rikaart, A.M., Kahn, R.S., Hoek, H.W. \& Sommer, I.E. (2011). Can lowfrequency repetitive transcranial magnetic stimulation really relieve medication-resistant auditory verbal hallucinations? Negative results from a large randomized controlled trial. Biol Psychiatry, 69(5), 450-456.

Slotema, C.W., Blorn, J.D., Hoek, H.W. \& Sommer, I.E. (2010). Should we expand the toolbox of psychiatric treatment methods to include repetitive transcranial magnetic stimulation (rTMS)? A meta-analysis of the efficacy of rTMS in psychiatric disorders. J Clin Psychiatry, 71(7), 873-884.

Stanford, A.D., Sharif, Z., Corcoran, C., Urban, N., Malaspina, D. \& Lisanby, S.H. (2008). Rtms strategies for the study and treatment of schizophrenia: A review. The International Journal of Neuropsychopharmacology, 11(4), 563-576.

Stevens, H.E., Smith, K.M., Rash, B. \& Vaccarino, F.M. (2010). Neural stem cell regulation, fibroblast growth factors, and the developmental origins of neuropsychiatric disorders. Frontiers in Neuroscience, 4(59), doi: 10.3389/fnins. 2010.00059

Storch, E.A., Mariaskin, A. \& Murphy, T.K. (2009). Psychotherapy for obsessive-compulsive disorder. Curr Psychiatry Rep, 11(4), 296-301.

Subramaniam, K., Luks, T.L., Fisher, M., Simpson, G.V., Nagarajan, S. \& Vinogradov, S. (2012). Computerized cognitive training restores neural activity within the reality monitoring network in schizophrenia. Neuron, 73(4), 842-853.

Takeuchi, H., Taki, Y., Sassa, Y., Hashizume, H., Sekiguchi, A., Fukushima, A. \& Kawashima, R. (2011). Working memory training using mental calculation impacts regional gray matter of the frontal and parietal regions. PLoS ONE, 6(8), e23175.

Talkowski, Michael, E., Rosenfeld, Jill, A., Blumenthal, I., Pillalamarri, V., Chiang, C., Heilbut, A., Ernst, C., Hanscom, C., Rossin, E., Lindgren, A.M., Pereira, S., Ruderfer, D., Kirby, A., Ripke, S., Harris, D.J., Lee, J.-H., Ha, K., Kim, H.-G., Solomon, Benjamin, D., Gropman, Andrea, L., Lucente, D., Sims, K., Ohsumi, Toshiro, K., Borowsky, Mark, L., Loranger, S., Quade, B., Lage, K., Miles, J., Wu, B.-L., Shen, Y., Neale, B., Shaffer, Lisa, G., Daly, Mark, J., Morton, Cynthia, C., Gusella \& James, F. (2012). Sequencing chromosomal abnormalities reveals neurodevelopmental loci that confer risk across diagnostic boundaries. Cell, 149(3), 525-537.

Tranulis, C., Sepehry, A.A., Galinowski, A. \& Stip, E. (2008). Should we treat auditory hallucinations with repetitive transcranial magnetic stimulation? A metaanalysis. Can J Psychiatry, 53(9), 577-586.

Tye, K.M. \& Deisseroth, K. (2012). Optogenetic investigation of neural circuits underlying brain disease in animal models. Nat Rev Neurosci, 13(4), 251-266.

van Veen, T., Goeman, J.J., Monajemi, R., Wardenaar, K.J., Hartman, C.A., Snieder, H., Nolte, I.M., Penninx, B.W.J.H. \& Zitman, F.G. (2012). Different gene sets contribute to different symp- 
tom dimensions of depression and anxiety. Am J Med Genet B Neuropsychiatr Genet, 159B(5), 519-528.

Vinogradov, S., Fisher, M. \& de Villers-Sidani, E. (2012). Cognitive training for impaired neural systems in neuropsychiatric illness. Neuropsychopharmacology, 37(1), 43-76.

Vinogradov, S., Fisher, M., Holland, C., Shelly, W., Wolkowitz, O. \& Mellon, S.H. (2009a). Is serum brain-derived neurotrophic factor a biomarker for cognitive enhancement in schizophrenia? Biol Psychiatry, 66(6), 549-553.

Vinogradov, S., Fisher, M., Warm, H., Holland, C., Kirshner, M.A. \& Pollock, B.G. (2009b). The cognitive cost of anticholinergic burden: Decreased response to cognitive training in schizophrenia. Am J Psychiatry, 166(9), 1055-1062.

Wagner, T., Valero-Cabre, A. \& Pascual-Leone, A. (2007). Noninvasive human brain stimulation. Апnu Rev Biomed Eng, 9, 527-565.

Weinberger, D.R. (1987). Implications of normal brain development for the pathogenesis of schizophrenia. Arch Gen Psychiatry, $44(7), 660-669$.
Wilkinson, L.S., Davies, W. \& Isles, A.R. (2007). Genomic imprinting effects on brain development and function. Nat Rev Neurosci, 8(11), 832-843.

Wykes, T., Huddy, V., Cellard, C., McGurk, S.R. \& Czobor, P. (2011). A meta-analysis of cognitive remediation for schizophrenia: Methodology and effect sizes. Am J Psychiatry, 168(5), 472485 .

Yizhar, O., Fenno, L.E., Prigge, M., Schneider, F., Davidson, T.J., O'Shea, D.J., Sohal, V.S., Goshen, I., Finkelstein, J., Paz, J.T., Stehfest, K., Fudim, R., Ramakrishnan, C., Huguenard, J.R., Hegemann, P. \& Deisseroth, K. (2011). Neocortical excitation/inhibition balance in information processing and social dysfunction. Nature, 477(7363), 171-178.

Zatorre, R.J., Fields, R.D. \& Johansen-Berg, H. (2012). Plasticity in gray and white: Neuroimaging changes in brain structure during learning. Nat Neurosci, 15(4), 528-536. 